\title{
Determination of Some Physical and Mechanical Properties of the Wood-Based Panels Modified by Acrylic Textile Fiber
}

\author{
Mustafa Altunok' ${ }^{1}$ Ihsan Kureli', Mehlika Pulat ${ }^{2}$ \\ ${ }^{1}$ Technology Faculty, Gazi University, Ankara, Turkey \\ ${ }^{2}$ Faculty of Science, Gazi University, Ankara, Turkey \\ Email:altinok@gazi.edu.tr, ikureli@gazi.edu.tr, mpulat@gazi.edu.tr
}

Received 18 September 2014; accepted 7 June 2015; published 10 June 2015

Copyright (C) 2015 by authors and Scientific Research Publishing Inc.

This work is licensed under the Creative Commons Attribution International License (CC BY). http://creativecommons.org/licenses/by/4.0/

c) (7) 0pen Access

\begin{abstract}
In this research, a series of wood-based panels were produced by using wood chips [beech (Fagus Sylvatica L.) and Scotch pine (Pinus sylvestris L.)] as wastes of wood-working workshops and acrylic fibers as wastes of textiles factory. Four kinds of different panels (Eltapan I, II, III and IV) were obtained by mixing these components in different composition $(0 \%, 25 \%$ and $50 \%)$. Some physical and mechanical properties of the samples taken from these panels were determined in accordance with ASTM D1037-12 and ASTM-C 1113. The values were compared to properties of industrially produced chipboard. As a result, the textile fibers used as additive material reduced density, thermal conductivity and bending resistance of wood panel and increased dimensional stability of wood panel.
\end{abstract}

\section{Keywords}

Modification, Acrylic Fiber, Wood Chips, Wood Based Composites, Density, Thermal Conductivity, Dimensional Stability, Bending Strength

\section{Introduction}

Forest and other natural assets have been used in producing the items that are needed from time immemorial. While use of natural wood material decreased gradually, the use and production of wood-based panels increased by expanding. Wood-based panels developed in order to provide dimensional stability and to obtain large-size sheet [1]. These panels are produced for protection against moisture and vermin as supplemented with natural or synthetic substances, as are produced in the form of wood chips mixed with various ingredients (fiber cement board). 
Animal wool, cotton and synthetic fibers are the basic material of textile production. The main features of these items include durability, length, flexibility, moisture absorption, resistance to heat and light, and being easily washable [2].

Acrylic fiber is a synthetic fiber that closely resembles wool in its character [3]. According to the definition of the ISO (International Standards Organization) and BISFA (International Synthetic Fiber Standardization Office), fibers which contain a minimum of $85 \%$ acrylonitrile in their chemical structure are called "Acrylic Fibers".

Acrylic fibers are soft and light fibers having light and warm tactile feeling to the human skin [4]. They are widely used, making the most of their characteristics, for knitted products such as sweater and jersey; bedding textiles such as blankets and Pile sheets; and carpets for home-uses. In addition, rag animals and western wigs are the products making use of acrylic fibers

Some important properties of acrylic fibers are: 1 -Lighter than wool fibers, and fabric hand with bulkiness; 2-Superior in warm retention, light and warm; 3-Superior in elastic recovery, and resistant to crease; 4Excellent in color development and can be dyed in desired color; 5-Little affected by sunlight; 6-Resistant to chemicals and cannot be attacked by molds and insects; 7-Thermoplastic [5].

Acrylic fiber is composed of acrylonitrile and a co monomer. The co monomer is added to improve dyeability and the textile processability of the acrylic fiber. It can be used $100 \%$ alone, or in blends with other natural and synthetic fibers [6]-[8].

Today, the cost, excellence and availability of raw materials are of principal importance. Due to environmental concerns, a very large number of companies are currently developing manufacturing processes using alternative materials for their crop and in search of new markets for the sub-products of their first-line production. Textile industry is an example of the reality that the industry is living these days. The textile industry has taken an increasing interest in developing a system for recycling waste fiber which results from the process of manufacturing product such as textile fabrics and fibers, non-woven fabrics etc. However, because of the lack of effective recycling technique, most of these wastes are currently destroyed by fire or buried underground [9].

The results showed that laminate produced using epoxy and reinforced with carbon fiber had the highest technological properties [10].

Bending strength and flexibility were increased on the composite material (gluelam) with glass fiber reinforced [11].

In the experiments, heat conductivity constant was determined according to ASTM C 1113-90 Hot Wire Method standards [12]. The least conductivity of temperature was detected on MDF coated by melamine impregnated decorative paper and the most conductivity of temperature was detected on HDF covered by high pressured laminate [13].

At the University of Minnesota and some Institutions in a Corporation "Mineral Bonded Composite Panel Research Initiatives and Projects" at the name of research done in the similar timber modification is known that [14].

The main purpose of this study is to prepare a series of modified panels by mixing the wood chips (beech (Fagus sylvatica L.) and Scotch pine (Pinus sylvestris L.)) and acrylic fibers. These components are collected from the wood-working workshop and textile manufactories as industrial waste materials. It is planned to obtain four types of modified panel by changing the ratio of wood chips and acrylic fibers. Another aim of this study is to investigate some physical and mechanical properties of the modified panels and to compare the values with the industrially produced panels.

\section{Material and Method}

In this research wood based panels were produced from a mixture of wood chips and textile waste of acrylic fibers. Urea formaldehyde glue was used to hold the components together. Certain physical and mechanical properties of the panels were determined and the features were compared to the industrially produced particleboard.

\subsection{Materials}

\subsubsection{Acrylic Fibers}

Characteristics of acrylic have many appealing properties. Acrylic's high performance makes it one of the fastest growing fibers in the outdoor, performance apparel categories. This fiber draws moisture away from the skin 
and quickly transports it to the surface making the wearer more comfortable. Other characteristics of acrylic include: quick drying time, excellent color fastness, UV resistance, soft hand luxurious touch \& drape warmth in thermal constructions easy care bulk without extra weight resistance to weathering durability resilience shape retention stain resistance wrinkle resistance and resistance to shrinking, fading, aging, chemicals, oils, moths, mildew, and fungus. Uses of Acrylic not only have many appealing characteristics and advantages, but many apparel, home furnishings, and industrial end uses as well. This fiber accounted for 5 percent of the fiber produced in the United States in 1990 with only three companies producing it at the time [15].

Some basic properties of acrylic fibers were presented in Table 1.

\subsubsection{Coarse and Fine Wood Chips}

Coarse wood chips in roughing planning machines (Moulder) and the fine wood chips in band saw machines on a separate collection system have been booked during processing application workshops beech wood and pine wood at the Gazi University Faculty of Technology Wood Products Industrial Division. Coarse and fine wood chips collected and purified from impurities in amounts necessary for each panel in Table 1 have been classified in accordance with the principles. This is classified in separate containers to air dry shavings to balance the degree of humidity (12\%) were kept in the room until the air conditioning. The length of coarse chips $3-4 \mathrm{~mm}$ and a thickness of at least $1 \mathrm{~mm}$; the lengths of fine chips $1-2 \mathrm{~mm}$, thickness as less than $0.5 \mathrm{~mm}$ were measured.

\subsection{Preparation of the Modified Panels}

Four types of modified panels (Eltapan-I, Eltapan-II, Eltapan-III, Eltapan-IV) were produced by mixing acrylic waste materials and fine-coarse wood chips fiber in different proportions (Table 2).

In preparing textile fiber panels (fiber + wood panel representing the "Eltapan" has been called) joined textile fiber and wood chips mixture of $25 \%$ urea formaldehyde glue and hardener (glue resin: Kaurit and hardener: Ammonium sulphate, Germany).

Textile fibers which can be distributed homogeneously were cut in $10 \mathrm{~mm}$ long. Draft panels have produced from basic materials of a homogeneous mixture of obtained wood chips-glue-textile fiber. The mixture pressed $2.5 \mathrm{~N} / \mathrm{mm}^{2}$ pressure and temperature conditions of $90^{\circ} \mathrm{C}$ for 45 min (OTT brands, hot press, Germany). Basic materials content and ratios of panels in Table 2, the images of the photographs in Figure 1 and production phases in Figure 2 are given.

Table 1. Some basic properties of acrylic fibers [16].

\begin{tabular}{ll}
\hline The glass transition point & $30^{\circ} \mathrm{C}$ to $75^{\circ} \mathrm{C}$ (water) from $50^{\circ} \mathrm{C}$ to $100^{\circ} \mathrm{C}$ (dry) \\
Melting point & $250^{\circ} \mathrm{C}$ \\
Density & 1.14 to $1.19 \mathrm{~g} / \mathrm{cm}^{3}$ \\
Copy strength & 2.3 to $3.1 \mathrm{kN} / \mathrm{dtex}$ (copolymer), 3.4 to $3.6 \mathrm{kN} / \mathrm{dtex}$ (homopolimer) \\
Copy percent elongation at & $20 \%-48 \%$ (copolymer), 30\% - 34\% (homopolimer) \\
Under normal conditions, Humidity & $0.5 \%$ \\
Less resistance against acids. & \\
Hot bases are yellowing. & \\
DMF, DMA, are soluble in solvents such as alcohol type is affected by the solvents. \\
Resistant to Light and outdoor weather conditions.
\end{tabular}

Table 2. The amounts (\%) of the components used to prepare the panels.

\begin{tabular}{|c|c|c|c|c|c|}
\hline Panel & Textile fiber & Coarse wood chips (beech) & Coarse wood chips (pine) & Fine wood chips (beech + pine) & Glue \\
\hline Eltapan-I & 25 & 25 & 25 & $\ldots$ & 25 \\
\hline Eltapan-II & 25 & $\ldots$ & $\ldots$ & 50 & 25 \\
\hline Eltapan-III & 25 & $\cdots$ & 50 & $\ldots$ & 25 \\
\hline Eltapan-IV & 25 & 50 & $\ldots$ & $\ldots$ & 25 \\
\hline Ind. Chipboard & \multicolumn{5}{|c|}{ Industrially produced and compared with the Eltapan panel board. } \\
\hline
\end{tabular}




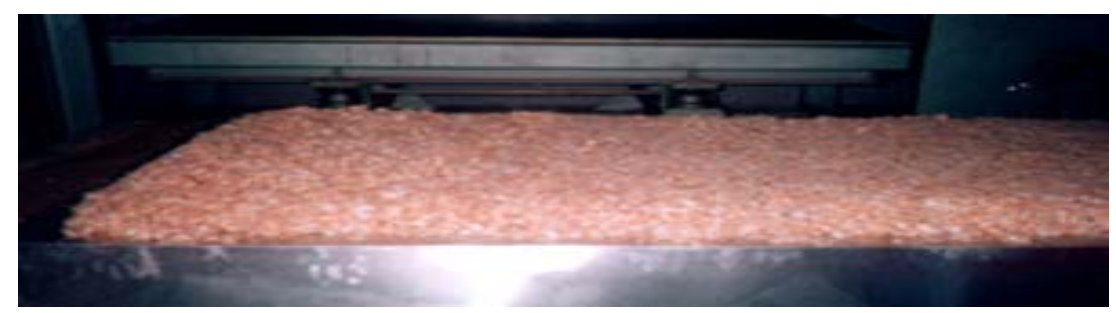

Figure 1. Preparation of mixture of the panel and pressing.

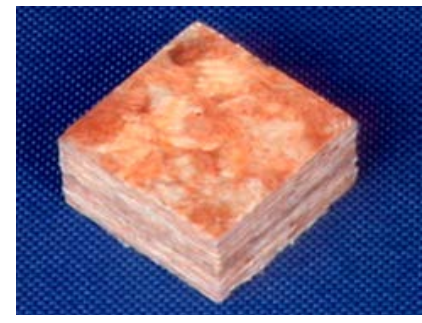

(a)

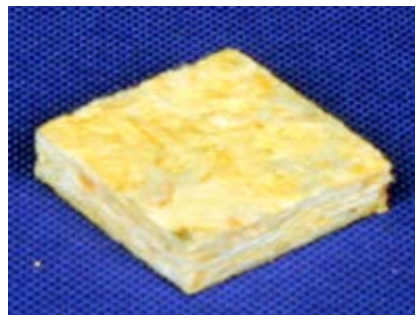

(b)

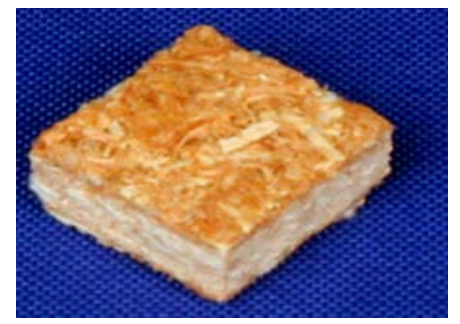

(c)

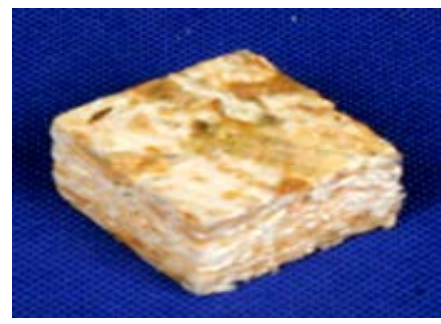

(d)

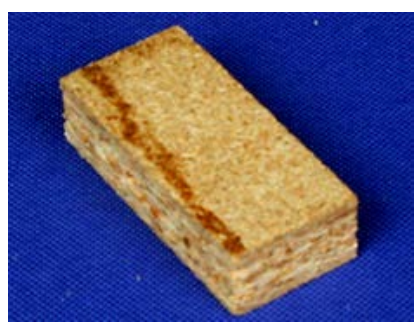

(e)

Figure 2. Produced and test samples. (a) Eltapan-I, (b) Eltapan-II, (c) Eltapan-III, (d) Eltapan-IV, (e) Industrial chipboard.

The Extruded panels were conditioned at temperature of $20^{\circ} \mathrm{C} \pm 2^{\circ} \mathrm{C}$ and relative humidity of $65 \% \pm 5 \%$ for providing equilibrium moisture content of $12 \%$.

The standard sizes for the test to be applied in pre-cut test samples in airtight plastic containers were stored until testing phase.

\subsection{Test Method}

Tests were applied by 4 tons capacity of Universal Testing Device at $800 \mathrm{kp}$ stage according to ASTM-D143-83 [17] standards at the laboratory of Technology Faculty in Gazi University. Rate of progress of the experimental device was set to receive $2 \mathrm{~mm}$ distance in a minute. Maximum forces were recorded $(\mathrm{N})$. In this study, applied tests are given to samples that are produced from modified panels (Eltapan I, Eltapan II, Eltapan III and Eltapan IV) and industrial chipboard obtained and application based on the standards in Table 3.

\subsection{Evaluation of Data}

In order to determine the effects, contents of textile fiber and wood chips mixture amounts \% were performed.

\section{Results}

\subsection{Density}

The average density values of modified panels and industrial chipboard which were determined according to ASTM D1037-12 [18] and presented in Table 4.

According to Table 4, while the density of Eltapan-IV (from the modified panels) is higher than the industrial chipboard, other panels are lower. 


\subsection{Water Absorption and Thickness Swelling}

Average values of water absorption and thickness swelling of the samples were determined according to ASTM D1037-12 [18] and presented in Figure 3.

As seen in Table 5, while swellings in water of all panels in the first 20 hours change rapidly, change in swellings percentages after from $20^{\text {th }}$ hour are lesser. At the end of $55^{\text {th }}$ hour, while the highest swelling is determined in ELTAP II, the lowest swelling is determined in ELTAP III.

\subsection{Thermal Conductivity}

The coefficient of thermal conductivity is expressed as the quantity of heat that passes through a unit cube of the substance in a given unit of time when the difference in temperature of the two faces is $1^{\circ}$. Here, the heat conductivity coefficient $(\lambda)$ is expressed as $\mathrm{kcal} / \mathrm{hr} \cdot \mathrm{m} \cdot{ }^{\circ} \mathrm{C}[10]$.

The average value of thermal conductivity coefficient of modified panels and industrial chipboard which were

Table 3. The experimental investigation of panel properties and their standards.

\begin{tabular}{ccc} 
Specifications & Sample Number & Standards \\
\hline Specific gravity & $15 \times 5=75$ & ASTM D1037-12 \\
Water absorption and thickness swelling & $15 \times 5=75$ & ASTM D1037-12 \\
Thermal conductivity & $15 \times 5=75$ & ASTM-C 1113 \\
Bending strength & $15 \times 5=75$ & ASTM D1037-12 \\
\hline
\end{tabular}

Table 4. The average density values of the modified panel and industrial chipboard.

\begin{tabular}{cccccc}
\hline \multirow{2}{*}{ Samples } & \multicolumn{4}{c}{ Modified Panel } & Industrial chipboard \\
\cline { 2 - 4 } & Eltapan-I & Eltapan-II & Eltapan-III & Eltapan-IV & 0.65 \\
\hline Density $\left(\mathbf{g} / \mathbf{c m}^{3}\right)$ & 0.60 & 0.56 & 0.61 & 0.68 & 0.68 \\
\hline
\end{tabular}

Table 5. The average values for thermal conductivity coefficient and temperature changes of test panels.

\begin{tabular}{ccc}
\hline Samples $(\mathrm{X})$ & $\mathbf{t}\left({ }^{\circ} \mathrm{C}\right)$ & $\boldsymbol{\lambda}\left(\mathbf{k c a l} / \mathbf{m h} \cdot{ }^{\circ} \mathrm{C}\right)$ \\
\hline Eltapan-I & 29.6 & 0.1415 \\
Eltapan-II & 30.8 & 0.1233 \\
Eltapan-III & 30.0 & 0.1418 \\
Eltapan-IV & 30.0 & 0.1451 \\
Industrial Chipboard & & 0.1874 \\
\hline
\end{tabular}

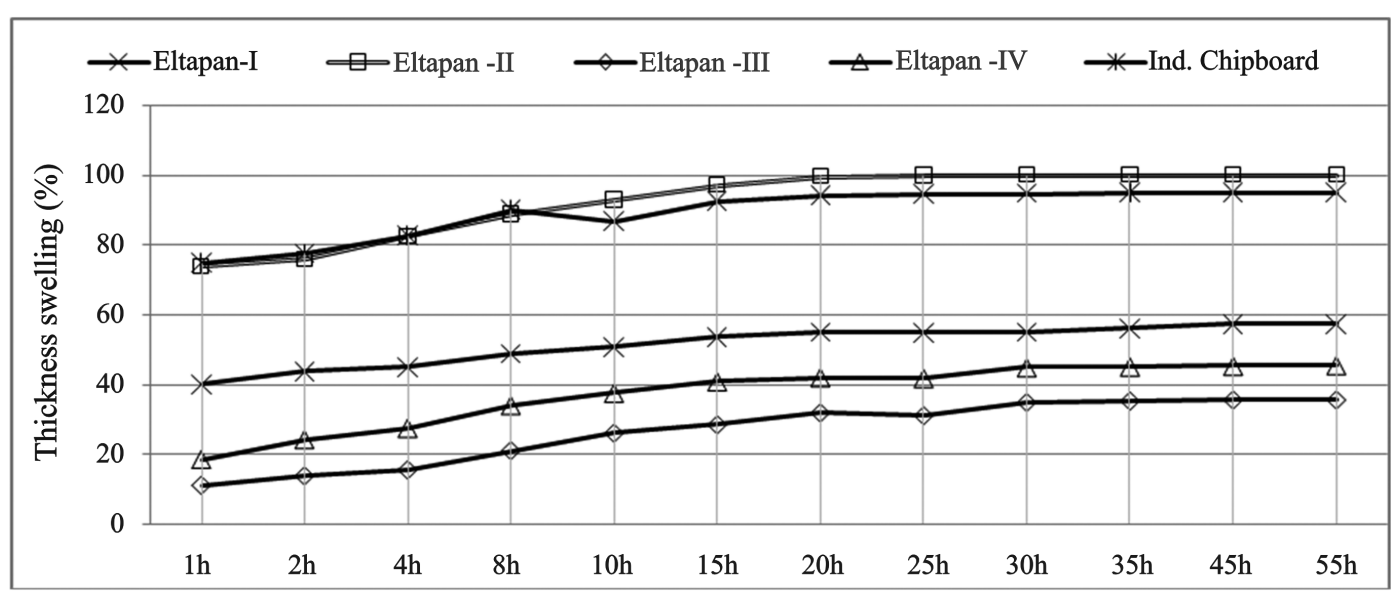

Figure 3. Average values of thickness swelling of the panels depend on time. 
determined according to the ASTM-C 1113 [12] in Table 5 were given.

As seen in Table 5, all the modified panels have a lower thermal conductivity according to the industrial chipboard.

\subsection{Bending Strength}

The average of bending strength of modified panels and industrial chipboard which were determined according to the ASTM D1037-12 in Table 6 were given.

As seen in Table 6, all the modified panels have a lower bending strength according to industrial chipboard.

\section{Conclusions and Recommendations}

All of the average values of swelling, density, thermal conductivity coefficient and bending strength of modified panels and industrial chipboard which were determined according to the ASTM D1037-12 [18] and ASTM-C 1113 [12] were given in Table 7.

The density values of modified panels and industrial chipboard were measured, the highest value $\left(0.68 \mathrm{~g} / \mathrm{cm}^{3}\right)$ in industrial chipboard and $\left(0.65 \mathrm{~g} / \mathrm{cm}^{3}\right)$ in ELTAP IV, and the lowest value $\left(0.56 \mathrm{~g} / \mathrm{cm}^{3}\right)$ in ELTAP II was determined. Overall ranking from low to high:

Eltapan II > Eltapan I > ELTAPAN III > INDUSTRIAL PARTICLEBOARD > Eltapan IV

Eltapan-IV, the cause of the density being high in content of $50 \%$ coarse beech wood chips is taking place. Eltapan-II, the cause of the density being low in content of 50\% fine wood chips (beech and pine) is taking place.

The thickness swell of the modified panels \% ratios as measured. $100 \%$ of the maximum swollen thickness as well ELTAP II, 35.5\% for the lowest thickness as swelling ratio was also determined ELTAP III. Overall ranking from low to high:

\section{Eltapan III > Eltapan IV > ELTAPAN I > INDUSTRIAL PARTICLEBOARD $>$ Eltapan II}

ELTAPAN II contained in the swelling ratio of the thickness of thin beech wood chips panel said that upgrade. Micro fibrils of fine beech wood chips, the inner of the panel and therefore the water absorption of ELTAP II increase [13].

Swelling ratios of the thickness and density in the modified panels and industrial chipboard panels are shown in the graph of Figure 4.

Thermal conductivity coefficients of the modified panels and industrial chipboard were measured. The highest thermal conductivity coefficient $0.1451 \mathrm{kcal} / \mathrm{hr} \cdot \mathrm{m} \cdot{ }^{\circ} \mathrm{C}$ as well as ELTAP IV, the lowest thermal conductivity coefficient $0.1233 \mathrm{kcal} / \mathrm{hr} \cdot \mathrm{m} \cdot{ }^{\circ} \mathrm{C}$ was also determined as an ELTAP II. Overall ranking from low to high:

Table 6. The average values of panels bending strength.

\begin{tabular}{cc}
\hline Samples (X) & Bending Strength $\left(\mathbf{N} / \mathbf{m m}^{2}\right)$ \\
\hline Eltapan-I & 7.359 \\
Eltapan -II & 5.861 \\
Eltapan -III & 5.160 \\
Eltapan -IV & 14.910 \\
Industrial Chipboard & 27.7 \\
\hline
\end{tabular}

Table 7. All of the average values of technical specification of modified panels and industrial particleboard.

\begin{tabular}{ccccc}
\hline Panels (X) & $\begin{array}{c}\text { Density } \\
\left(\mathbf{g} / \mathbf{c m}^{\mathbf{3}} \mathbf{)}\right.\end{array}$ & $\begin{array}{c}\text { Swelling } \\
\mathbf{( \% )}\end{array}$ & $\begin{array}{c}\text { Thermal Conductivity Coefficient } \\
\left(\mathbf{k c a l} / \mathbf{h r m} \mathbf{~}^{\mathbf{C}} \mathbf{)}\right.\end{array}$ & $\begin{array}{c}\text { Bending Strength } \\
\left(\mathbf{N} / \mathbf{m m}^{\mathbf{2}} \mathbf{)}\right.\end{array}$ \\
\hline Eltapan-I & 0.60 & 57.4 & 0.1415 & 7.36 \\
Eltapan-II & 0.56 & 100.0 & 0.1233 & 5.86 \\
Eltapan-III & 0.61 & 35.5 & 0.1418 & 5.16 \\
Eltapan-IV & 0.65 & 45.4 & 0.1451 & 14.91 \\
Industrial Chipboard & 0.68 & 94.8 & 0.1874 & 27.7 \\
\hline
\end{tabular}




\section{Eltapan II > Eltapan I > ELTAPAN III > Eltapan IV > INDUSTRIAL PARTICLEBOARD}

The thermal conductivity coefficient $\left(0.1233 \mathrm{kcal} / \mathrm{hr} \cdot \mathrm{m}{ }^{\circ} \mathrm{C}\right)$ of Eltapan II was low, that it comprises a low density and content of $50 \%$ fine wood chips components.

Thermal conductivity coefficients and density in the modified panels and industrial chipboard panels are shown in the graph of Figure 5.

Bending strength of the modified panels and industrial chipboard was determined. The highest bending strength $14.910 \mathrm{~N} / \mathrm{mm}^{2}$ on the Eltapan IV (industrial chipboard: $27.7 \mathrm{~N} / \mathrm{mm}^{2}$ ), while the lowest bending strength values were calculated $5.160 \mathrm{~N} / \mathrm{mm}^{2}$ on the Eltapan III. Overall ranking from low to high:

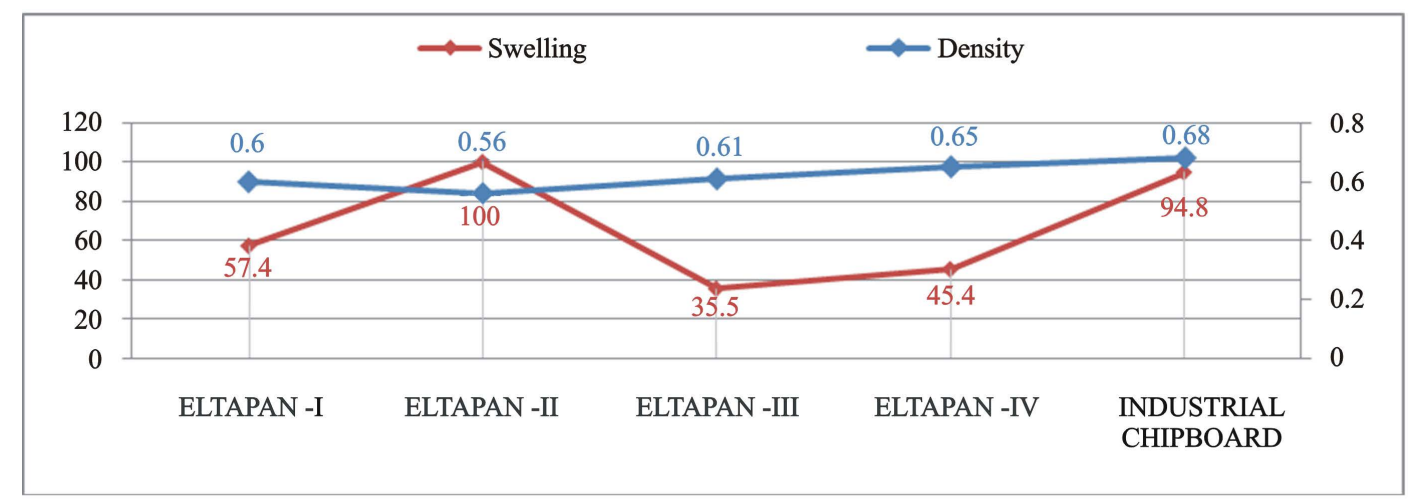

Figure 4. Swelling ratios of the thickness and density in the modified panels and industrial chipboard panels.

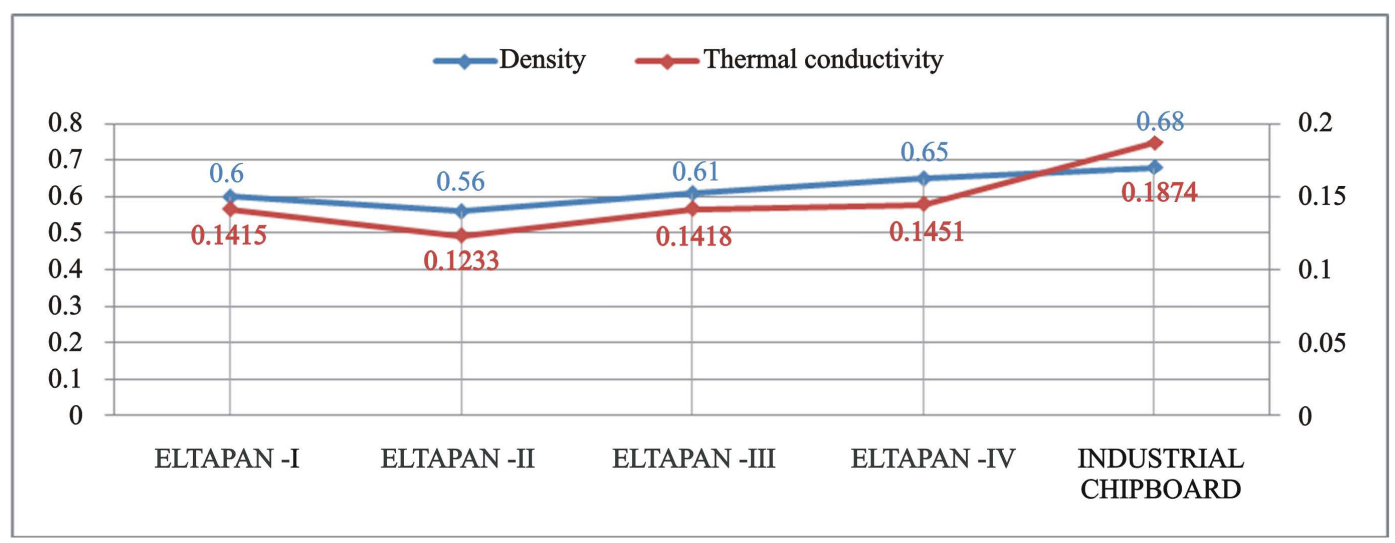

Figure 5. Thermal conductivity coefficients and density in the modified panels and industrial chipboard panels.

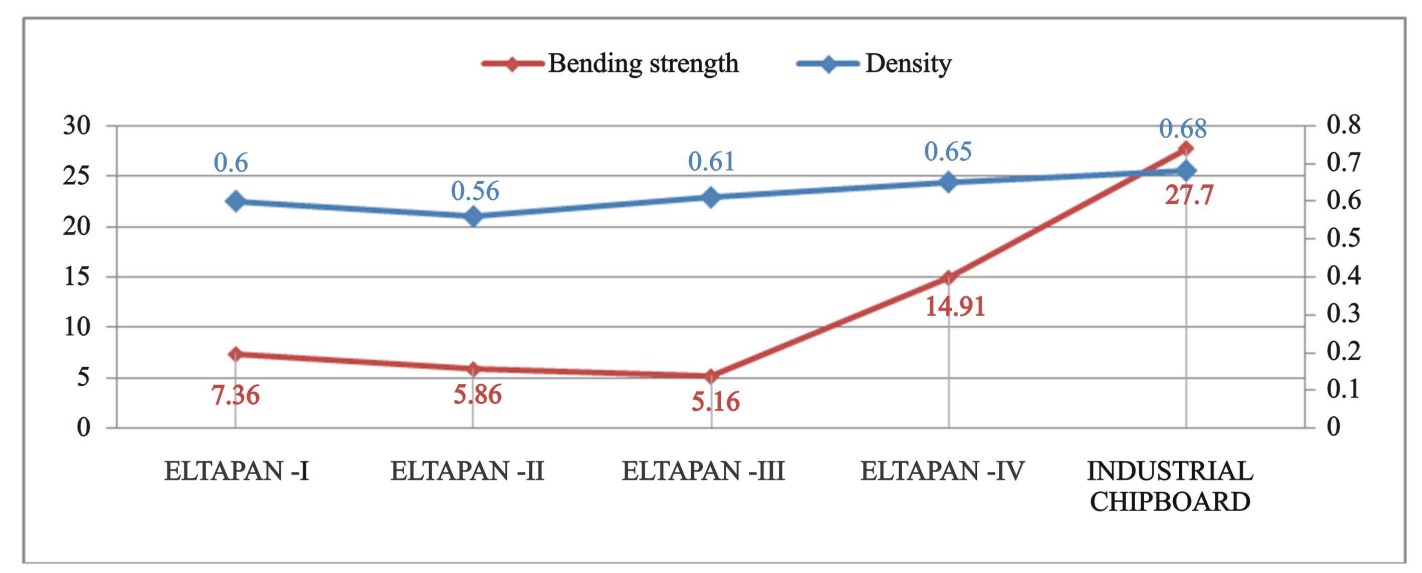

Figure 6. Bending strength and density in the modified panels and industrial chipboard panels. 


\section{Eltapan III > Eltapan II > Eltapan I > ELTAPAN IV > INDUSTRIAL PARTICLEBOARD}

Bending strength on the Eltapan IV was higher (from modified panels). The reason for this, the Eltapan IV is the content of $50 \%$ coarse beech wood chips and high density $\left(0.65 \mathrm{~g} / \mathrm{cm}^{3}\right)$. Bending strength and density in the modified panels and industrial chipboard panels are shown in the graph of Figure 6 .

The optimum properties of the ELTAP IV of modified panels recommended for general use. The IV ELTAP of modified panels has of maximum bending strength, in water swelling value is half of industrial chipboards and thermal conductivity is also low. Eltapan II is the most suitable for the isolation use

\section{References}

[1] 10th Annual Forestry, Wildlife and Natural Resources Research Review "Critical Natural Resource Issues Affecting Minnesota Forests”, Natural Resources Research Institute, Cloquet Forestry Center January 16, 2013.

[2] Stueben, K. (1970) Part I, High Polymers Series Vol. XXIV. In: Leonard, E.C., Ed., Vinyl and Diene Monomers, Wiley-Interscience, New York, Chapt. 1, 181.

[3] Palit, S.R., Guha, T., Das, R. and Konar, R.S. (1965) Vol. 2. In: Bikales, N.M., Ed., Encyclopedia of Polymer Science and Technology, John Wiley \& Sons, Inc., New York, 229.

[4] Capone, G.J. and Masson, J.C. (2004) Encyclopedia of Polymer Science and Technology, Acrylic Fibers. John Wiley \& Sons, Inc., Vol. 9, 1-39. http://dx.doi.org/10.1002/0471440264

[5] Knudsen, J.P. (1963) The Influence of Coagulation Variables on the Structure and Physical Properties of an Acrylic Fiber. Textile Research Journal, 33, 13-20.

[6] Karakişla, M. and Saçak, M. (1998) Grafting of Ethyl Acrylate onto Monofilament Polyester Fibers Using Benzoyl Peroxide. Journal of Applied Polymer Science, 70, 1701-1705. http://dx.doi.org/10.1002/(SICI)1097-4628(19981128)70:9<1701::AID-APP7>3.0.CO;2-K

[7] Sacak, M. and Celik, M. (1996) Hydrogen Peroxide Initiated Grafting of Acrylamide onto Poly(ethylene terephthalate) Fibers in Benzyl Alcohol. Journal of Applied Polymer Science, 59, 1191-1194.

[8] Ongun, N., Karakışla, M., Aksu, L. and Saçak, M. (2004) Graft Polymerization of Methacrylamide onto Poly(ethylene terephthalate) Fibers with Benzoyl Peroxide as Initiator and their Characterization. Macromolecular Chemistry and Physics, 205, 1995-2001. http://dx.doi.org/10.1002/macp.200400178

[9] Velosa, J., Fanguerio, R., Martins, N., Fernandes, M. and Soutinho, F. (2013) Waste Fiber Reinforced Composite Materials: Production and Mechanical Properties. Materials and Science Forum, 730-732, 665-670. http://dx.doi.org/10.4028/www.scientific.net/MSF.730-732.665

[10] Berkel, A. (1970) Wood Material Technology. Istanbul University, Forest Faculty, 319.

[11] Güler, C. and Subaşi, S. (2011) Carbon and Glass Fiber Reinforced Laminated Scots Pine (Pinus sylvestris L.), I. Ulusal Akdeniz Orman ve Çevre Sempozyumu, 26-28 Ekim.

[12] ASTM C1113/C1113M-09 (2013) Standard Test Method for Thermal Conductivity of Refractories by Hot Wire (Platinum Resistance Thermometer Technique).

[13] Fiorelli, J. and Dias, A. (2006) Fiberglass-Reinforced Glulam Beams: Mechanical Properties and Theoretical Model. Materials Research, 9, 263-269. http://dx.doi.org/10.1590/S1516-14392006000300004

[14] Açik, C. and Tutuş, A. (2012) Effects of Various Synthetic Surface Coatings on Thermal Conductivity of Fiberboard. Ormancılık Dergisi, 8, 1-8.

[15] Kadolph, S.J., Langford, A.L., et al. (1998) Textiles. 8th Edition, Prentice-Hall, Inc. imon \& Schuster/A Viacom Company, New Jersey, 118, 121.

[16] Synthetic Fiber/Physical and Chemical Properties of Acrylic. http://textilefashionstudy.com/synthetic-fiber-physical-and-chemical-properties-of-acrylic

[17] ASTM-D 143-83 (1983) Standard Methods of Testing Small Clear Specimens of Timber.

[18] ASTM D1037-12 (2012) Standard Test Methods for Evaluating Properties of Wood-Base Fiber and Particle Panel Materials. 